This item was submitted to Loughborough's Research Repository by the author.

Items in Figshare are protected by copyright, with all rights reserved, unless otherwise indicated.

\title{
Demonstration of a novel pulsed electric field technique generating neither conduction currents nor joule effects
}

PLEASE CITE THE PUBLISHED VERSION

http://dx.doi.org/10.1109/TPS.2013.2293915

PUBLISHER

(C) IEEE

VERSION

AM (Accepted Manuscript)

\section{PUBLISHER STATEMENT}

This work is made available according to the conditions of the Creative Commons Attribution-NonCommercialNoDerivatives 4.0 International (CC BY-NC-ND 4.0) licence. Full details of this licence are available at: https://creativecommons.org/licenses/by-nc-nd/4.0/

\section{LICENCE}

CC BY-NC-ND 4.0

\section{REPOSITORY RECORD}

Novac, Bucur M., Fahd Banakhr, Ivor R. Smith, Laurent Pecastaing, Robert Ruscassie, Antoine Silvestre De Ferron, and Pascal Pignolet. 2019. "Demonstration of a Novel Pulsed Electric Field Technique Generating Neither Conduction Currents nor Joule Effects". figshare. https://hdl.handle.net/2134/20449. 


\title{
Demonstration of a novel pulsed electric field technique generating neither conduction currents nor Joule effects
}

\author{
B M Novac, Senior Member, IEEE, F Banakhr, Student Member, IEEE, \\ I R Smith, Senior Member, IEEE, L Pecastaing, R Ruscassié, A De Ferron and P Pignolet
}

\begin{abstract}
This paper is devoted to a detailed presentation of all aspects involved in a demonstration of a novel pulsed electric field technique that does not generate conduction currents or Joule effects. Details are given of both the experimental arrangement and the electro-optic Kerr-effect based diagnostic used in the measurement of the intense pulsed electric fields in water. The results show unequivocally that the novel technique is effective in significantly reducing the initial concentration of Escherichia coli bacteria. Finally, a brief comment on the way ahead is provided.
\end{abstract}

Index Terms-Pulsed Electric Field (PEF) sterilization, microbial inactivation, electro-optic devices, Kerr effect.

\section{INTRODUCTION}

$\mathrm{T}_{(\mathrm{s})}^{\mathrm{h}}$ he first results in the application of pulsed electric field (PEF) research to food processing appeared some fifty years ago [1], but more recently use of this technique for industrial liquid (or 'pumpable') food sterilization has been widely investigated. Noteworthy results have been reported by Old Dominion University, Washington State University and Ohio State University in the USA, Kumamoto University in Japan, the Technische Universität Berlin, in Germany, the Technical University of Delft in the Netherlands and the Efremov Institute in Russia. In the UK, important research was undertaken by pulsed power groups at Strathclyde University and more recently at Loughborough University, when results providing a first step towards clarifying the mechanism for the lethality of ns-duration electric field pulses on prokariotes were reported [2].

Very briefly, the action of a PEF on a biological cell can be explained by considering its effect on membranes, the outer or plasma membrane and the inner membranes separating subcellular structures such as the nucleus. The membranes

Manuscript received 2012

B. M. Novac, F. Banakhr and I. R. Smith are with the School of Electronic, Electrical and Systems Engineering, Loughborough University, Loughborough, Leicestershire LE11 3TU, UK (phone: +44(0)1509-227-048; fax: 44(0)1509-227-014; e-mail: B.M.Novac@ lboro.ac.uk)

L. Pecastaing, R. Ruscassié, A. Silvestre De Ferron and P. Pignolet are with the Laboratoire SIAME, Equipe Génie Electrique, Université de Pau et des Pays de l'Adour, Hélioparc Pau-Pyrénées, 2 av Angot 64053 Pau cedex 9, France (e-mail: laurent.pecastaing@univ-pau.fr) isolate regions of different materials, whilst at the same time facilitating the flow of selected ions and molecules between them $[3,4]$. The outer membrane is a good electrical insulator and the application of a relatively high electric field (a few tens of $\mathrm{kV} / \mathrm{cm}$ ) for a time comparable with its characteristic RC time (e.g., about $1 \mu \mathrm{s}$ ) results in a charge redistribution and the buildup of a trans-membrane voltage. Once this reaches a threshold of approximately $1 \mathrm{~V}$, the outer membrane permeability increases and cell death may result, by a phenomenon termed irreversible electroporation. More recent studies predicted and demonstrated experimentally that sterilisation of bacteria such as Escherichia coli can also be achieved using very intense transient electric fields (of the order of $100 \mathrm{kV} / \mathrm{cm}$ and higher) with a pulse duration of the order of the charging time of intracellular structures of the microorganism (i.e., tens of ns) [5,6]. It is however well beyond the aims of this paper to comment on the complex processes involved in such phenomena.

Commercially available systems for PEF processing (e.g., $[7,8])$ all use irreversible electroporation, with a pulsed power generator having a high pulse rate producing the required voltage pulses. The liquid is passed through a relatively large number of treatment chambers or cells, in each of which it is exposed to a series of pulses. In each cell there is a pair of electrodes between which the electric field is applied and which are in direct contact with the liquid. This technology is therefore termed invasive, and it can only be used with liquid food! A significant feature is that, due to the temperature maintained during the processing (no more than $60^{\circ} \mathrm{C}$ ), the flavour of the product is much better preserved than in products processed using conventional pasteurization. Although very effective, the present invasive PEF industrial systems have a series of important drawbacks, detailed later, of which the most important are related to their large energy consumption due to heating of the processed liquid and the fact that only liquid foods can be processed.

The main aim of the present paper is to provide experimental evidence of the efficacy of a novel PEF processing technique, which not only ensures the lowest energy consumption possible for PEF sterilization but, at least in principle, opens for the first time the way for the processing solid pre-packed food! 
The paper firstly presents the major drawbacks in the standard invasive PEF technique [9], which triggered a joint Loughborough University (UK)-Pau University (France) research programme [10]. The implementation of a non-invasive PEF technique (i.e., one that does not require any kind of electrodes) in the food industry is however a difficult, complex and costly task. To encourage funding, while also reducing the associated risk and as a first step of the research programme, it was decided to perform demonstrative experiments to establish unequivocally the fact that conduction currents are not required. The paper presents all the associated challenges that had to be overcome before a reliable and practical arrangement was achieved. The main results obtained during the research campaign are presented, undoubtedly establishing the effectiveness of the novel technology. Finally, the future steps towards implementing the technique at an industrial prototype scale are briefly presented.

\section{INVASIVE PEF TECHNOLOGY: THE MAIN DRAWBACKS}

To help in understanding the differences, Figures 1(a) and (b) show the schematic arrangement for sterilizing water for both the presently used invasive and a future non-invasive PEF technique. In the first scenario, a pulsed power generator applies a high-voltage impulse across two metallic electrodes immersed inside the water sample; a current is generated through the liquid along with an electric field and Joule energy is deposited during the discharge of the generator. In the second scenario a remote source (e.g., an antenna) produces an electric field inside the water sample, with no conduction current (either electronic or ionic) being present. In both cases the temperature of the liquid is very important, with higher temperatures increasing the effectiveness of the PEF treatment by inducing a structural fatigue of the cell membranes and thus making them more susceptible to electrical breakdown. This synergy is used in practice with the liquid usually being preheated to around $\mathrm{T}=313 \mathrm{~K}\left(40{ }^{\circ} \mathrm{C}\right)$ prior to being PEF processed.

In what follows, the most important drawbacks related to industrial PEF systems applied invasively to liquid (pumpable) food are outlined.

\section{A. Joule (thermic) effect and energy consumption}

As already indicated, all PEF systems presently in use are invasive, with currents from a few hundreds amperes to more than one kiloampere flowing through the liquid during processing. The deposited Joule energy causes the local temperature of the liquid to rise substantially and obviously implies very large energy consumption. In some cases external cooling is required to avoid the liquid reaching pasteurization temperatures, further increasing the overall energy consumption.

\section{B. Electrode effects}

The inter-electrode current inherent in the invasive PEF technology may also generate unwanted and significant side effects. For example hydrolysis may introduce metal particles from the metallic electrodes into the food [11] or produce toxic chemicals such as hydrogen peroxide (which ironically, helps in killing micro-organisms!) [11].

The distance between a pair of electrodes in a processing cell should be as short as possible to minimize the applied voltage and therefore the energy consumption. However, this presents an obstacle to any 'chunks' present in the liquid food being treated.

A number of important issues also relate directly to the electrodes, such as the need for regular cleaning due to the formation of surface deposits, replacement because of corrosion every 100 hours or so and, most importantly, because of accidental electrical breakdown.

\section{Electric field direction}

The available literature indicates that there is an electrical orientation effect $[12,13]$ and therefore, to produce a given level of decontamination for food contaminated with rod-shaped bacteria by a field applied radially, requires pulses having an increased intensity over a field applied axially. Fluid turbulence is therefore generated in industrial PEF systems to ensure that the bacteria are attacked at various angles as they pass through the treatment cells, where the only direction of the applied electric field is across the two electrodes.

\section{NON-INVASIVE PEF TECHNOLOGY: MAIN ADVANTAGES, THE CHALLENGE AND THE NEED FOR A PROOF-OF-PRINCIPLE EXPERIMENT}

\section{A. Energy considerations and the challenge}

If no electrical breakdown is present, no ionic and electronic currents are produced through the treated samples during a non-invasive PEF treatment, apart from the unavoidable generation of displacement currents $\varepsilon_{0} \varepsilon_{r} \frac{\partial \boldsymbol{E}}{\partial t}$, where $\varepsilon_{\mathrm{r}}$ is the relative permittivity of the sample. Therefore, no temperature rise is expected, even following the application of a very large number of electrical pulses. This implies a very important reduction in the energy consumption making the non-invasive method, at least in principle, extremely energy efficient. It is obvious that to avoid an electrical breakdown in water, the applied electric field pulse has to be fast. However, according to [5] the shorter the pulse duration $\tau$, the more intense is the electric field required for lysing i.e., $E \sim \tau^{-1 / 3}$. Further following [5] in the case of invasive PEF and for an arbitrary pulse, the electrical energy density required is $W_{\text {invasive }}=\sigma \tau E^{2}$, where $\sigma$ is the sample conductivity and therefore the energy density decreases for shorter pulses i.e., $W_{\text {invasive }} \sim \tau^{1 / 3}$. This is not the case for non-invasive $\mathrm{PEF}$, where the energy density dissipated during processing is not a function of the pulse duration. It is important to note that, due to this fact, the increase in energy efficiency from invasive to non-invasive PEF strongly depends on the pulse shape (see Appendix 1).

In conclusion, non-invasive PEF processing mainly depends on the ability of the pulsed power system to generate sufficiently intense electric fields. However, the remote generation of intense electric fields inside food samples immersed in water and having a relative permittivity of around 60 is not easy and presents the major challenge to the application of this novel 


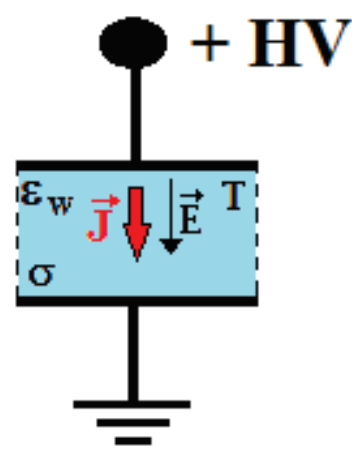

(a)

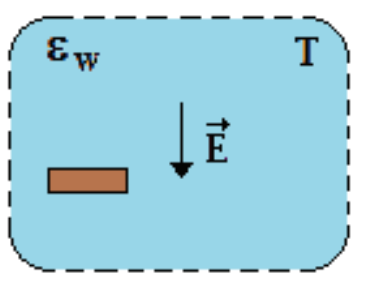

(b)

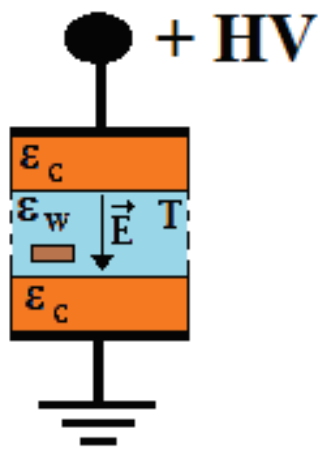

c)

Fig. 1 PEF techniques for sterilizing water, having relative permittivity $\varepsilon_{\mathrm{w}}$, conductivity $\sigma$ and temperature $\mathrm{T}$

a) Invasive technique; a pair of metallic electrodes are positioned inside water; a pulsed power generator applies a high-voltage impulse (HV); during processing an ionic current density $\boldsymbol{J}$ and an electric field $\boldsymbol{E}$ are both generated inside the water sample, with $\boldsymbol{J}=\sigma \boldsymbol{E}$

b) Non-invasive technique; a remote source, such as a pulsed power generator feeding an impulse antenna (for simplicity these components are not shown), produces an intense electric field $\boldsymbol{E}$ inside the water sample; displacement currents $\varepsilon_{0} \varepsilon_{w} \frac{\partial \boldsymbol{E}}{\partial t}$ are always present, but no electronic or ionic currents exist

(c) Present PEF arrangement; a pair of metallic electrodes are both covered with thick ceramic material (dielectric barriers) having a relative permittivity $\varepsilon_{\mathrm{c}} \gg>\varepsilon_{\mathrm{w}}$, and therefore are not in direct contact with the water sample; a pulsed power generator applies a high-voltage impulse (HV); during processing an intense electric field $\boldsymbol{E}$ is generated inside the sample, together with a displacement current produced during the charging and discharging of the two ceramic elements and the water; for fast (tens of ns) impulses, as far as electrical breakdown of the water sample is avoided, no conduction (i.e., electronic or ionic) currents are being generated

Note that for both (b) and (c), due to the possibility of scaling up the treatment volume, PEF treatment of solid pre-packed food immersed in the water (shown as brown rectangles) is in principle possible.

technology.

Once this obstacle is overcome, the possibility of generating 2-dimensional fields will remove the need to create artificial turbulence and will help in simplifying the system design and increasing the processing efficiency.

\section{B. More advantages}

When using non-invasive technology the problems mentioned above related to metallic electrodes are all eliminated since, at least in principle, no part of the equipment is in direct contact with the food being processed. As a consequence, much more generous volumes can be processed and the method is certainly not limited to liquid food (see the rectangular solid samples shown in Fig. 1). This may turn out to be actually the most important advantage of the non-invasive method! When successfully applied in practice, the non-invasive method will allow pre-packed food (both liquid and solid) to be processed in a special room on supermarket premises, thereby increasing the shelf life and reducing the (accepted) traditional losses. The reduction in wasted food would certainly provide a very significant economy. Another important application of the non-invasive PEF method could be to speed-up the ageing process of bottled wine [14] and the number of areas of further possible application could be very much larger.

\section{The need for proof-of-principle experiments}

A comprehensive survey of the available PEF literature shows that practically all authors agree that the electric field plays a major role in the observed reduction in the number of microbes during processing of liquid samples. However, a number of issues related to the localized thermal effects of the electric current raise the very justified question: what is the contribution to sterilization brought about by the large electric currents generated during an invasive PEF processing? In [5] it is suggested that: '...the viability of $E$. coli is mainly determined by the electric field, rather than by the current density in the suspension' (the underlining does not appear in the original), but others [15] suggest the opposite: '...it is believed that electroporation is not the only killing mechanism associated with pulsed electric field sterilization.... The current through the orange juice is believed to be a strong contributing factor for these results'. A definite answer to this question is of extreme importance for the future of the non-invasive PEF technique. The considerable technical effort required to develop the novel technology to an industrial level is not justifiable without undoubtedly demonstrating that effective PEF processing can be achieved using only electric fields, in the complete absence of ionic or electronic (i.e., conduction) currents and their corresponding Joule effect. The present work is dedicated to obtaining an answer to just this issue.

\section{PRACTICAL ARRANGEMENT FOR THE PEF EXPERIMENTS}

\section{A. Principle of the present PEF cell}

Fig. 1 (c) shows the schematic of the PEF cell used in the present experiments. When compared with the standard invasive PEF processing cell of Fig. 1(a), the major change is 
the presence of dielectric barriers mounted on the two metallic electrodes, thereby separating the electrodes from the water to be treated. This arrangement was firstly described and theoretically analyzed in $[16,17]$. The barriers were made from ceramic material having a relative permittivity $\varepsilon_{c}=3200$, much larger than the permittivity of water $\varepsilon_{w}=73$ [18], both values corresponding to a temperature of $40^{\circ} \mathrm{C}$. The experiments used water with a conductivity of about $\sigma=500 \mu \mathrm{S} / \mathrm{m}$. The time constant $\varepsilon_{0} \varepsilon_{\mathrm{w}} / \sigma \approx 1.3 \mu \mathrm{s}$ is much larger than the pulse duration (less than $100 \mathrm{~ns}$ ) and therefore the displacement current dominates and the conduction current can safely be ignored. The arrangement, acting like an electrostatic lens, enables the electric field to be concentrated in the water sample and not in the ceramic. It also limits the electric current flowing through the cell to the values dictated by the displacement currents generated during charging and discharging the cell, even in the case that the water sample suffers an electrical breakdown. Related to the analysis presented in [16] it is important to note that actually, due to the fast electric field impulse, there is no time for any net flow of electric charge. This is due to the fact that the characteristic field relaxation time defined in [16] and calculated for the present experimental data as $8.5 \mu \mathrm{s}$, is much larger than the time of application of the electric field impulse of less than $100 \mathrm{~ns}$. The accumulation of free (unpaired) electrical surface charge along the dielectric-liquid interface is therefore not possible.

\section{B. Mechanical arrangement}

Fig. 2 (a) shows the PEF cell used during the present experiments, generated by a Maxwell 3D electrostatic solver. The two cylindrical ceramic elements, with a diameter of $35.2 \mathrm{~mm}$ and a height of $11.7 \mathrm{~mm}$, are covered with a $4.2 \mathrm{~mm}$ thick plastic sheath. One of their circular flat sides has a thin metallic film deposited on its surface and connected to a metallic electrode. A $4 \mathrm{~mm}$ thick acrylic cylinder maintains the two ceramic elements coaxial at an axial distance of $d_{w}=3 \mathrm{~mm}$. The cylinder has two holes across a diagonal, covered with glass windows, enabling a laser beam to pass through. The remaining space between the two ceramics elements, of $4.48 \mathrm{~cm}^{3}$ volume, is filled with water containing the Escherichia coli. The assembled cell is positioned inside a plastic bath (Fig. 2 (b)), filled with water maintained at $40^{\circ} \mathrm{C}$ (Fig. 2(c)) and with the two electrodes, electrically connected to the pulsed power generator.

\section{Pulsed power generator and electrical diagnostics}

The pulsed power source uses a trigger generator type TG-70 (L-3 Sciences [19]), in which a $0.1 \mu \mathrm{F}$ capacitor can be charged to $70 \mathrm{kV}$ and discharged into three, parallel-connected, $50 \Omega$ / 5 ns high-voltage coaxial cables through a $\mathrm{SF}_{6}$ pressurized trigatron (Fig. 3). The PEF cell is connected to one of these cables and, because its impedance is much larger than the characteristic impedance of the cable, a number of high-voltage reflections are generated (Fig. 4(a)). In the present experiments a crowbar surface breakdown switch, installed in parallel with the PEF cell, is used to obtain a single voltage impulse with amplitude close to twice the charging voltage of the TG-70 capacitor. A single voltage impulse not only allows a comparison to be made with invasive PEF literature data (see below) but, as discussed later, also reduces the chances of electrical breakdown inside the cell. The voltage waveforms in Fig. 4 were recorded on a $300 \mathrm{MHz}$ digital oscilloscope using a North Star voltage probe type PVM 6, having a maximum pulsed voltage and frequency of $100 \mathrm{kV}$ and $80 \mathrm{MHz}$ [20] and an accuracy better than $1.5 \%$. The measurement of the current flowing through the PEF cell was attempted using high-bandwidth current monitors type Pearson 2877 [21] (sensitivity 1V/A, bandwidth $300 \mathrm{~Hz}-200 \mathrm{MHz}$, rise time $2 \mathrm{~ns}$ ), with results also shown in Fig. 4. However, due to the fact that this type of current monitor can only measure safely currents up to about $100 \mathrm{~A}$, it was necessary to split one of the cables connecting the cell to the pulsed generator into parallel wires. To ensure the same current flows through each of these, the wires were mounted symmetrically along a cylindrical plastic support and two identical current monitors were used to check that the wires actually shared the current equally.

\section{Equivalent electric circuit and the Joule energy deposited in water during $P E F$ processing}

The total Joule energy deposited in the water treated by PEF is one of the most important characteristics of the present experiments. Before an accurate value for this energy could be calculated, it was firstly necessary to measure the current and voltage and use the data, together with PSpice [22] modeling, to determine the values of the elements of the electrical circuit as shown in Fig. 3.

Fig. 4(a) shows the voltage across the cell and the current flowing through the cell. One can easily distinguish a first phase, when the cell is being charged to $77 \mathrm{kV}$, followed by the crowbar switch closure which discharges the cell. The PEF treatment is only performed during the first phase, as the voltage across the cell during the discharge phase is extremely low since the cell is effectively short-circuited.

Fig. 4(b) shows results obtained from a similar experiment, but with a modified cell for which the two ceramic elements were connected to each other by a conductive silver-loaded epoxy. No water is present in the cell (i.e., $d_{w}=0$ ) and it is therefore possible to obtain the Equivalent Series Resistance (ESR) for the ceramic material, as detailed below.

The total capacitance of the cell can be calculated considering three series-connected capacitors: two ceramic capacitors each of $C c=2.36 \mathrm{nF}$ and one water capacitor of $C w=0.25 \mathrm{nF}$, values obtained using a $3 \mathrm{D}$ electrostatic solver as presented later. Simple circuit analysis shows that only $C c /(2 C w+C c) \approx 0.82$ of the total voltage $\mathrm{V}$ applied to the cell electrodes actually appears on the water capacitor. This allows an estimate to be obtained for the electric field generated in water as $0.82 \mathrm{~V} / \mathrm{d}_{\mathrm{w}}$ and shows that for $1 \mathrm{~V}$ applied on the cell, an electric field of $273 \mathrm{~V} / \mathrm{m}$ is generated. However, a much more accurate calculation of the central electric field was obtained and used later by the same software already mentioned.

The self-inductance of the cell circuit is easily determined from the period of discharge of the current (Fig. 4(a)) as $475 \mathrm{nH}$. 


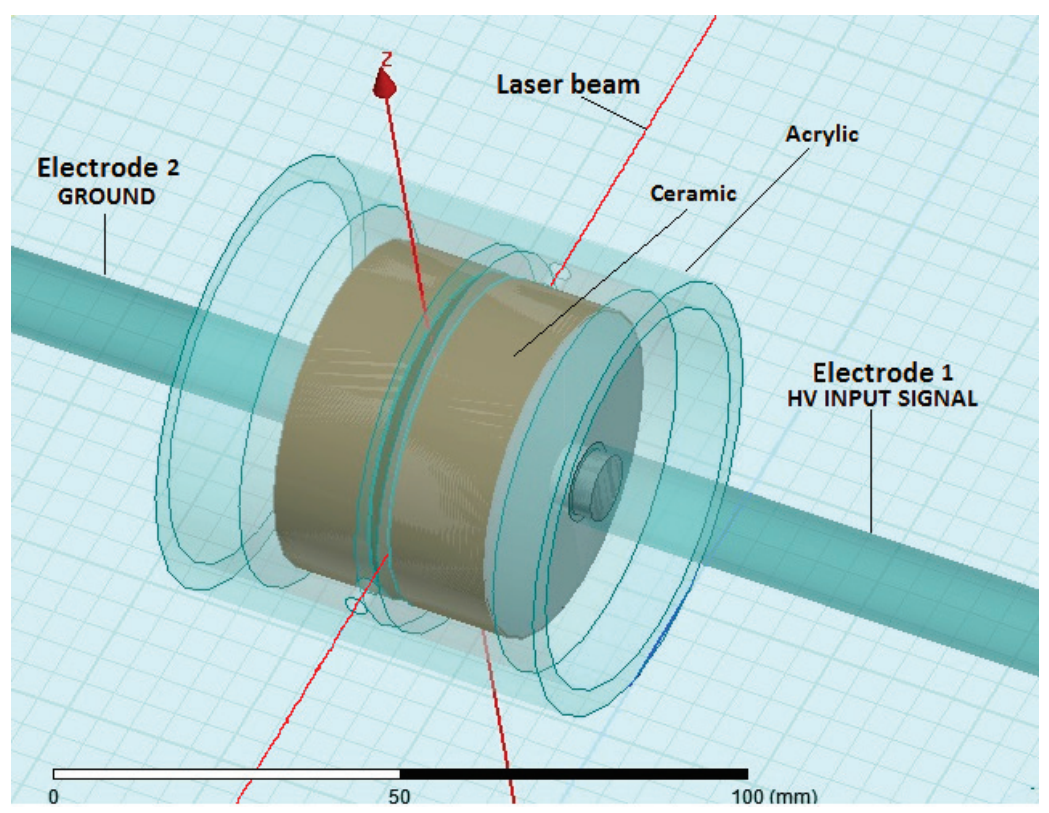

(a)

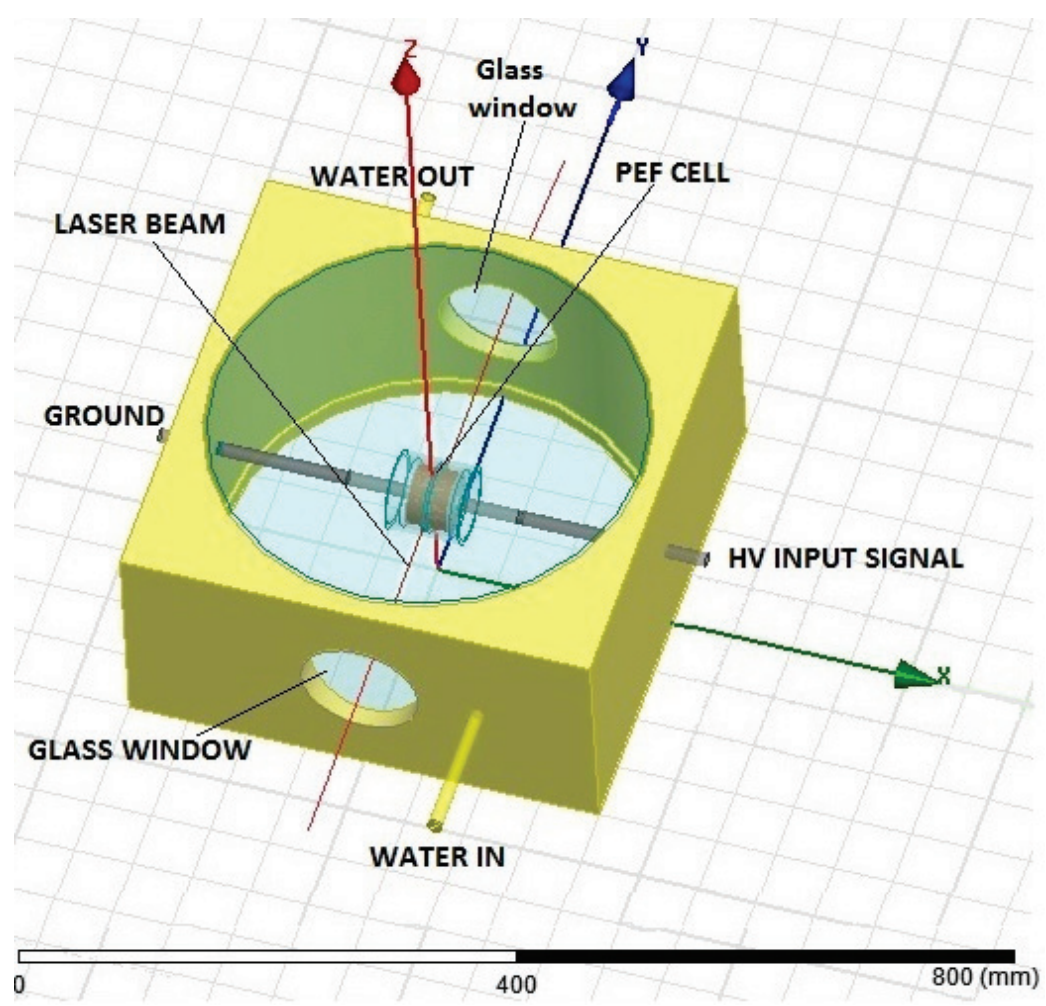

(b) 


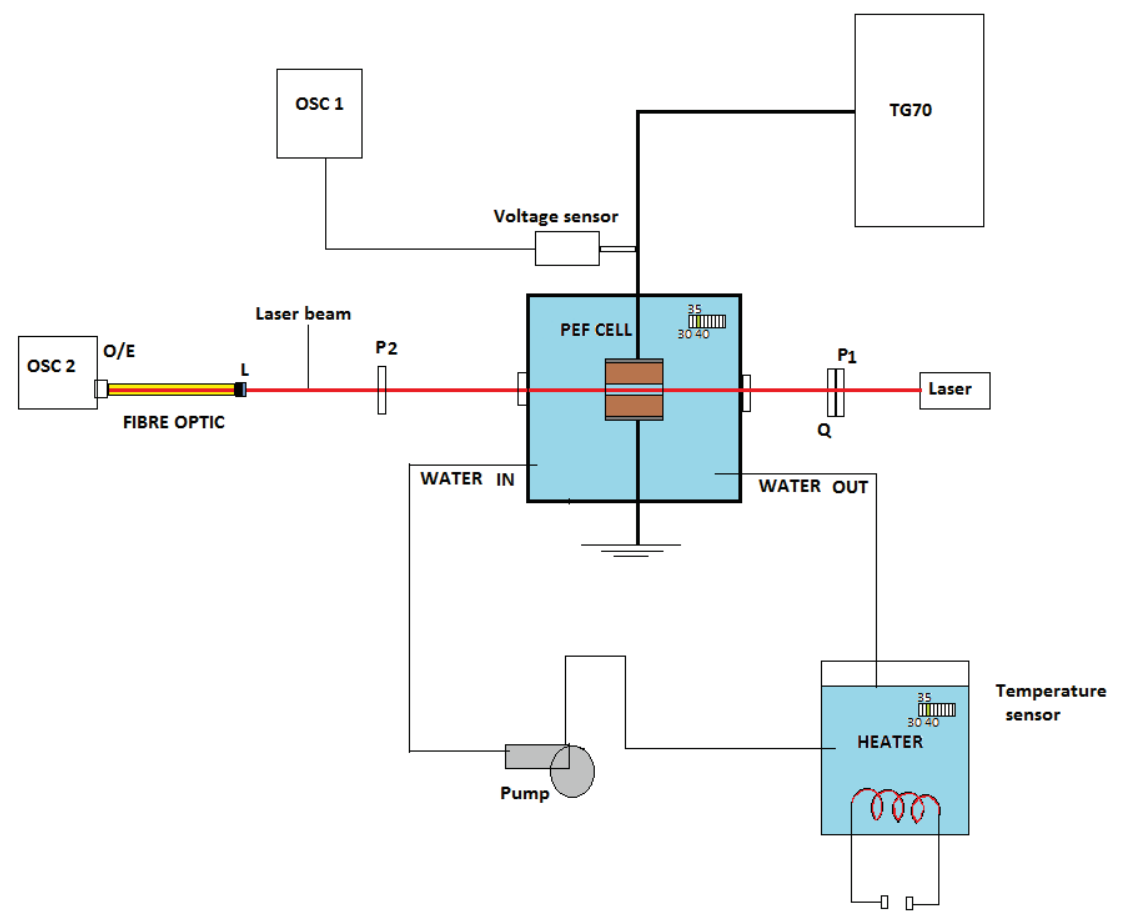

(c)

Fig. 2 Arrangement used in the PEF experiments

(a) drawing of the PEF cell generated by a Maxwell 3D electrostatic solver

(b) drawing of the cell mounted inside a plastic bath filled with water and attached to two electrodes connected to the pulsed power generator (not shown). In Cartesian coordinates $(\mathrm{x}, \mathrm{y}, \mathrm{z})$ the electric field and the metallic electrodes are all along the Ox axis and the laser beam is along the Oy axis.

(c) overall system (schematic, not to scale), including the water heating installation, the pulsed power generator (TG-70) with voltage diagnostic coupled to a digital oscilloscope (OSC) and the optical assembly used for the electric field diagnostics using the Kerr effect in water ( $\mathrm{L}$ is a collimating lens , P are polarisers and Q is a quarter wave-plate)

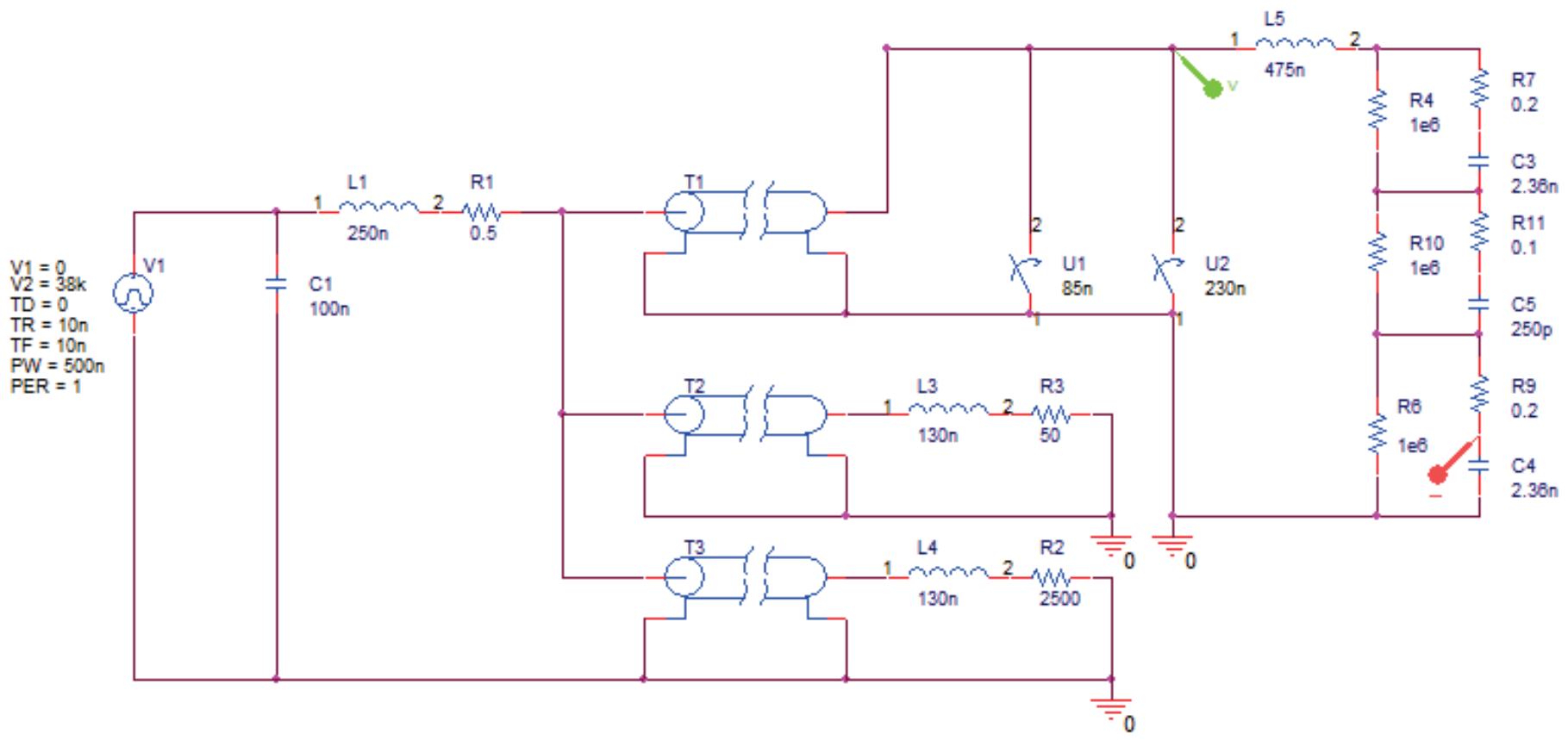

Fig. 3 PSpice model of the electrical system used in the PEF experiments

The TG-70 generator basically consists of a capacitor discharged through three long coaxial cables. The cell is connected at the end of one coaxial cable, in parallel with a crowbar switch, while the other two cables are simply terminated with resistors. See text for both the crowbar and cell models 


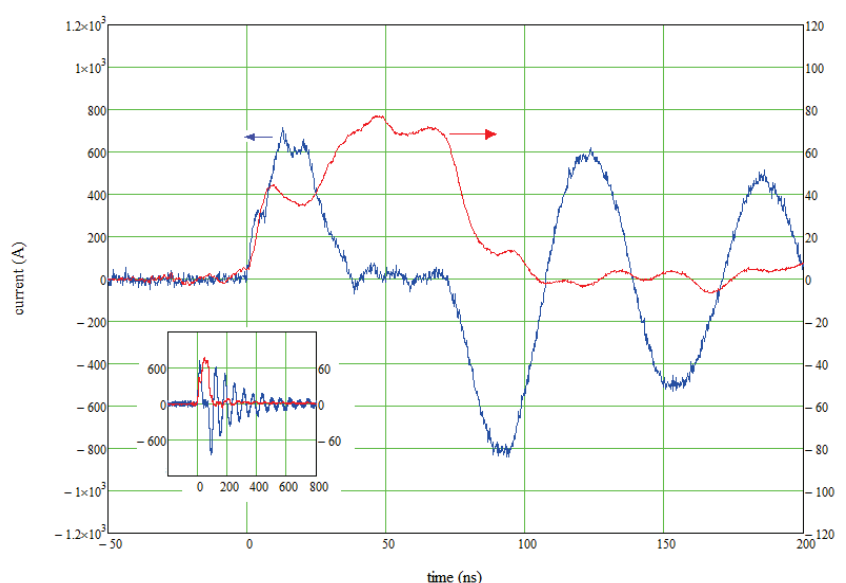

(a)

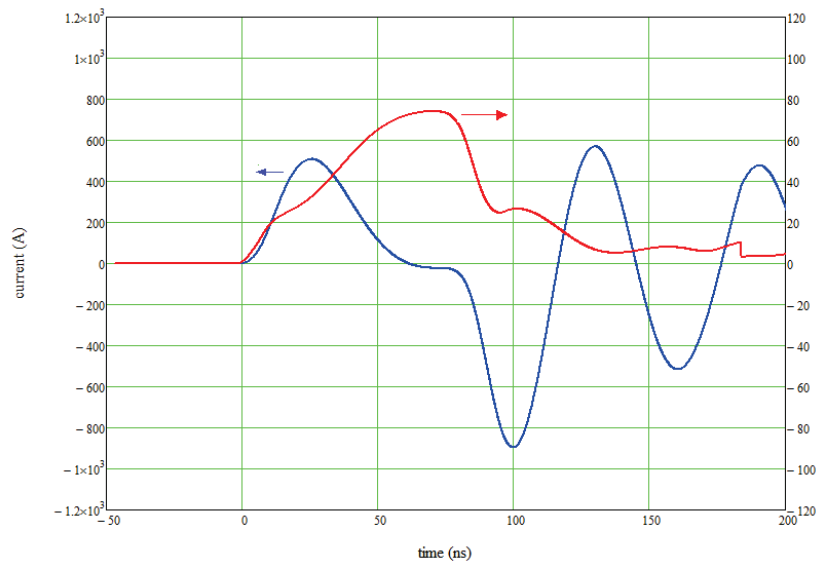

(c)

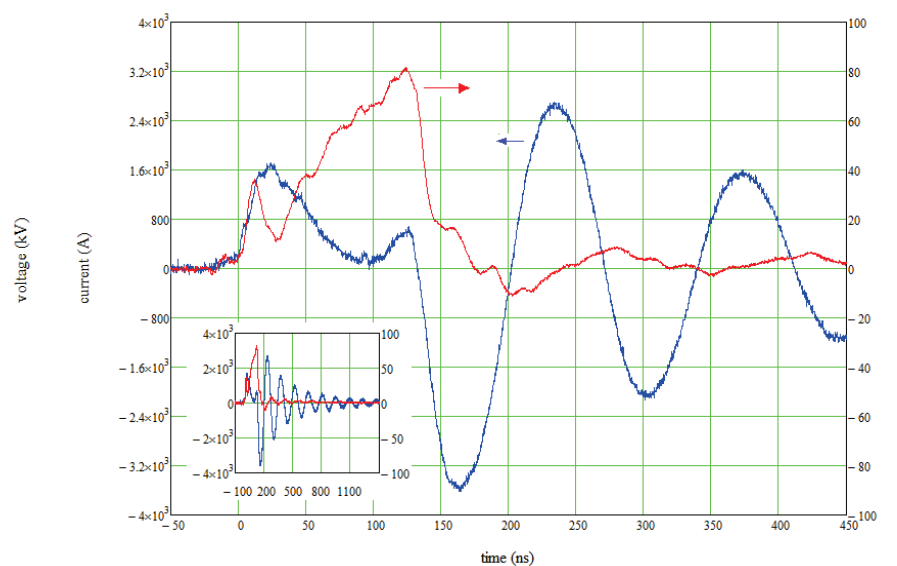

(b)

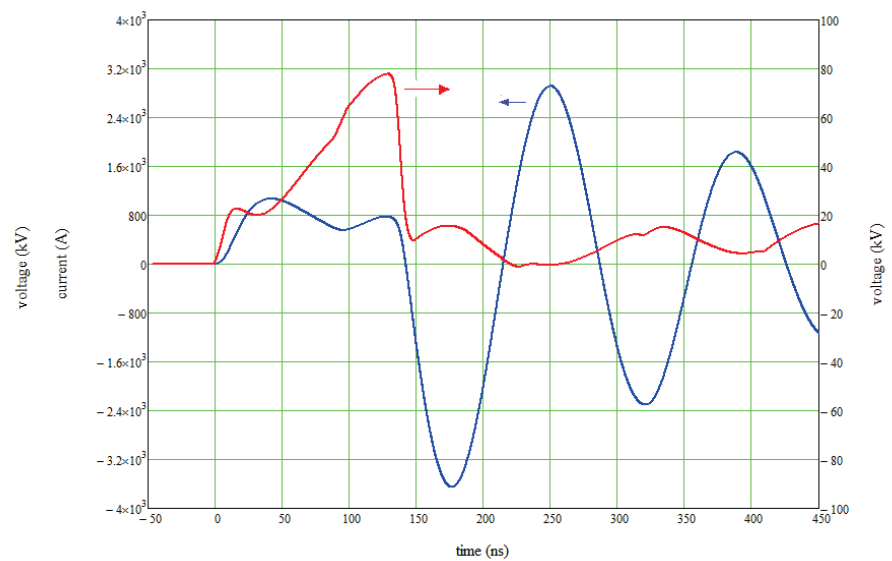

(d)

Fig. 4 Voltage impulse applied on the PEF cell by the TG-70 generator and the corresponding current flowing through the cell circuit: (a) normal cell with water (only the first $200 \mathrm{~ns}$ ); insert shows the complete time history of the discharge)

(b) cell without water, with ceramics connected to each other (only the first $450 \mathrm{~ns}$ ); insert shows the complete time history of the discharge

(c) PSpice prediction for the test presented in (a); (d) PSpice prediction for the test presented in (b)

Each of the three capacitors mentioned above has its own ESR and parallel resistance and since the parallel resistances are of the order of $1 \mathrm{M} \Omega$, they do not play any appreciable role. The total ESR for the two identical ceramics during the charging phase was obtained, using PSpice modeling and the data in Fig. 4(b), as about $0.4 \Omega$ i.e., $0.2 \Omega$ per ceramic element. This enabled the ESR of the water capacitor to be determined from Fig. 4(a)), again during the charging phase, as about $0.1 \Omega$. It is important to note that the same essential result for the ESR of water $\left(R_{w}^{E S R}\right.$ ) can also be obtained using the definition $R_{w}^{E S R}=X_{w} \tan \delta=\frac{1}{2 \pi f C_{w}} \tan \delta$. The frequency $f$ can be estimated from $f=\frac{0.35}{t_{\text {rise }}}$, where $t_{\text {rise }}$ is rise time of the displacement current impulse during the charging phase. Again using the data in Fig. 4(a), $\approx 31 \mathrm{MHz}$. Data from [18] shows that for water, at this frequency and $40{ }^{\circ} \mathrm{C}, \tan \delta \approx 0.005$. The resulting value of $R_{w}^{E S R}=0.12 \Omega$ is very close to the value obtained experimentally, giving high confidence in the result.
During the sinusoidal discharge phase, the ESR for water can again be calculated from the definition above, this time using the frequency determined form Fig. 4(a) data as $f \approx 16 \mathrm{MHz}$. The result is $0.24 \Omega$, but during this phase the relatively high resistance of the crowbar plasma dominates the cell circuit. For modeling the results shown in Fig. 4(a), the crowbar resistance was considered in the PSpice model to have a value of $1 \mathrm{G} \Omega$ before the switch closure and $13 \Omega$ after closure, dropping to $3.4 \Omega$ after another $145 \mathrm{~ns}$.

The predictions obtained using the PSpice model are presented in Fig. 4(c) and Fig. 4(d).

The Joule energy deposited in water during each phase can be calculated as $Q=R_{w}^{E S R} \int I^{2} d t$, where the ESR is considered to be a constant. Using the current data from Fig. 4(a) (see also insert), the integrals for each phase can be easily evaluated and the results indicate that during cell charging (i.e., during the application of PEF treatment) the energy is just $0.89 \mathrm{~mJ}$, while during the discharge it is $7.85 \mathrm{~mJ}$, resulting in a total Joule energy deposited in water of $8.74 \mathrm{~mJ}$. Neglecting any heat losses due to conduction phenomena, the temperature variation 
of the treated water during one PEF shot can be estimated as $\Delta T=\frac{Q}{m_{w} c_{p}}$, where $m_{w}=4.44 \mathrm{~g}$ is the water mass at a density of $992.2 \mathrm{~kg} / \mathrm{m}^{3}$ and $c_{p}=4178.5 \mathrm{~J} / \mathrm{kg} / \mathrm{K}$ is the constant-pressure heat capacity, both at $40{ }^{\circ} \mathrm{C}$. The result is $0.00047^{\circ} \mathrm{C}$ which shows that Joule effects can be completely neglected, even if a very large number of consecutive PEF shots is applied to the treated water sample one after another.

\section{E. Calculation of the $3 D$ electric field distribution}

The spatial distribution of the vector electric field for the arrangement presented in Fig 2 (a) and (b) was obtained using a Maxwell 3D electrostatic solver [23] (see Fig. 5). Fig. 5 (b) shows the variation of the component $E_{\mathrm{x}}$ along the laser path (i.e., the Oy axis). This shows that for $\mathrm{V}_{\mathrm{c}}=1 \mathrm{~V}$ applied to the cell, the electric field generated at the center is $\mathrm{k}_{\text {cell }} \cdot \mathrm{V}_{\mathrm{c}}=283 \mathrm{~V} / \mathrm{m}$, where $\mathrm{k}_{\text {cell }}=283 \mathrm{~m}^{-1}$ is a cell constant (obtained from Fig. 5(b)) and therefore about $\mathrm{V}_{\mathrm{c}}{ }^{\circ}=70 \mathrm{kV}$ needs to be applied (Fig. 4(b)) to generate $\mathrm{k}_{\text {cell }} \cdot \mathrm{V}_{\mathrm{c}}{ }^{\circ}=200 \mathrm{kV} / \mathrm{cm}$. It is interesting to note that, as expected, very intense fields are produced in a circular region at the water-ceramic-acrylic triple 'point'. This is most likely the cause of the surface electric breakdown along the acrylic tube reported below for a train of impulses with the central electric field reaching a peak of $225 \mathrm{kV} / \mathrm{cm}$. Although possible, no attempt was made to redesign the system to minimize this unwanted effect, but for safety reasons the train of impulses was reduced to a single pulse by using the crowbar described earlier.

\section{F. Electric field diagnostic using the Kerr effect in water}

In the very limited space available inside the cell, only one method is suitable for accurate electric field measurement: the laser-based Kerr effect in water. Although the measurement technique appears straightforward, an extensive research programme was necessary to clarify the accuracy of the measurement and to find the precise Kerr constant for water at room temperature [24]. The technical details of the electro-optical arrangement are presented elsewhere [24] and, because of the high homogeneity of the electric field inside the cell water, the cross section of the laser beam plays no role.

For clarity, it is sufficient to mention here that the Kerr effect is visualized as a time-varying light intensity $\mathrm{I}(\mathrm{t})$ that follows the Malus Law:

$$
\mathrm{I}(\mathrm{t})=\mathrm{I}_{\max } \sin ^{2}\left(\pi \mathrm{B} \int \mathrm{E}_{\mathrm{x}}(\mathrm{t}, \mathrm{y})^{2} \mathrm{dy}+\delta\right)
$$

where $I_{\max }$ is the maximum value of the light intensity and $E_{x}$ is the component perpendicular to the laser path of the time-varying vector electric field strength. The field integral is calculated along the laser path in water.

In Eq. (1) B is the Kerr 'constant' for water, which depends on the temperature, amongst other things. The preliminary experimental data, shown in Fig. 6, is in agreement with the temperature variation indicated in [25] as:

$$
\frac{\mathrm{B}(\mathrm{T})}{\mathrm{B}\left(\mathrm{T}_{\mathrm{ref}}\right)}=\mathrm{A}_{0}+\mathrm{A}_{1} / \mathrm{T}+\mathrm{A}_{2} / \mathrm{T}^{2}+\mathrm{A}_{3} / \mathrm{T}^{3}
$$

where $\mathrm{A}_{0}=255.46, \mathrm{~A}_{1}=-2.322 \cdot 10^{5} \mathrm{~K}, \mathrm{~A}_{2}=7.038 \cdot 10^{7} \mathrm{~K}^{2}$, and $A_{3}=-7.087 \cdot 10^{9} \mathrm{~K}^{3}$. The final results of the temperature study will be presented elsewhere. However, previous results [24] indicate that for room temperature $\mathrm{T}_{\mathrm{ref}}=295 \mathrm{~K}$, and at a wavelength of $658 \mathrm{~nm}$, the value is $\mathrm{B}\left(\mathrm{T}_{\text {ref }}\right)=2.45 \cdot 10^{-14} \mathrm{~m} / \mathrm{V}^{2}$. Using Eq (2), at $\mathrm{T}=313 \mathrm{~K}$, the corresponding B represents $87 \%$ of the room temperature value.

Finally, $\delta= \pm \pi / 4$ is an angular shift introduced by the presence of a quarter wave plate (Q in Fig. 2). The role of this is to increase the Kerr measurement precision [24] and, whenever used in the present work, the optical arrangement was made such that $\delta=-\pi / 4$.

For the particular arrangement used in this work, Eq. 1 can be conveniently re-written as:

$\mathrm{I}(\mathrm{t})=\mathrm{I}_{\text {max }} \sin ^{2}\left(\pi \mathrm{BE}_{\mathrm{w}}^{2}(t) l^{\prime}+\delta\right)$

where $E_{w}(t)=V(t) / d_{w}, V(t)$ is the transient voltage impulse applied to the cell (Fig. 4 (b) and $l^{\prime}=25.06 \mathrm{~mm}$ is the effective length of the laser path through water heated to $40{ }^{\circ} \mathrm{C}$ representing another cell constant and calculated from

$l^{\prime}=\left.d_{w}^{2} \int_{-l}^{l} E_{x}(y)^{2}\right|_{l V} d y$

The calculation in Eq. (4) takes into account the effects of fringing fields at the cell edges by evaluating the time invariant field integral for $1 \mathrm{~V}$ applied to the cell electrodes, using data from Fig. 5(b). In the field integral the distance $l=100 \mathrm{~mm}$ represents half of the entire laser path through water, from the cell center to the glass window of the plastic bath (Fig. 2 (b)), although the electric field is practically zero after about $60 \mathrm{~mm}$ (Fig. 5(b)). As presented below, the voltage signal can be unreliable and in such cases $E_{w}(t)$ is calculated from Eq. 3 using the Kerr signal $\mathrm{I}(\mathrm{t})$ and the time variation of the central electric field is obtained as:

$\mathrm{E}_{\text {center }}(\mathrm{t})=\mathrm{k}_{\text {cell }} \cdot \mathrm{d}_{\mathrm{w}} \cdot \mathrm{E}_{\mathrm{w}}(\mathrm{t})$

$G$. The paramount importance of the Kerr effect diagnostic in PEF experiments with no conduction current

When performing invasive PEF experiments, the application of a voltage impulse across two electrodes immersed in water guarantees generation of an electric field. However, in the case of the present PEF tests, this is not necessarily the case. Fig. 7 presents results obtained during preliminary testing at Pau using a Marx generator [26] to apply a train of voltage impulses to the cell and Fig. 7(a) illustrates a typical example, in which a peak electric field of $200 \mathrm{kV} / \mathrm{cm}$ is generated during the first impulse. The voltage signal across the cell can be used to obtain both the time varying central electric field and a prediction of the Kerr signal using Eq (3) (with $\delta=0$ i.e., no quarter wave plate present), both presented in Fig. 7(a). The fact that the real Kerr signal compares favorably with this prediction (Fig. 7(a)) gives considerable confidence in the experimental results. The small differences appearing after $200 \mathrm{~ns}$ are due to resistive losses inside the water and which are not taken into account.

However, for an experiment in which the electric field reaches $225 \mathrm{kV} / \mathrm{cm}$, the predicted and the real Kerr signals are quite different near the first peak, suggesting an anomaly, most likely a pre-breakdown phenomenon (Fig. 7 (b)). Indeed, as soon as the second peak is reached, a breakdown occurs inside the 


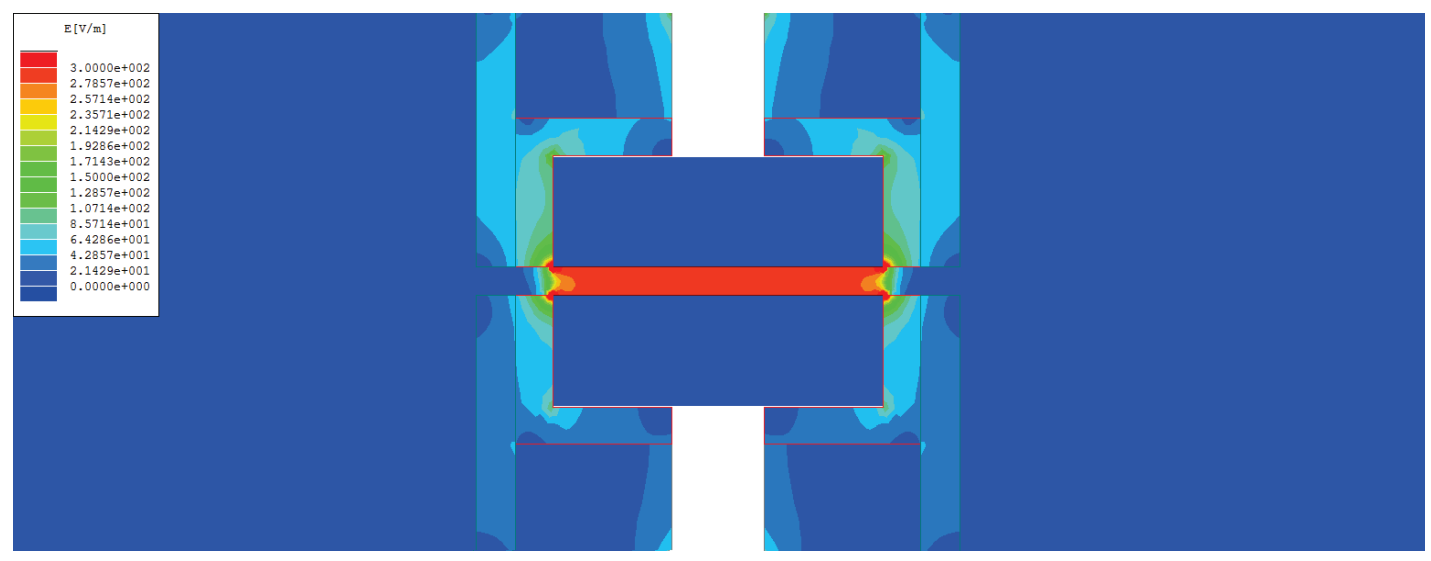

(a)

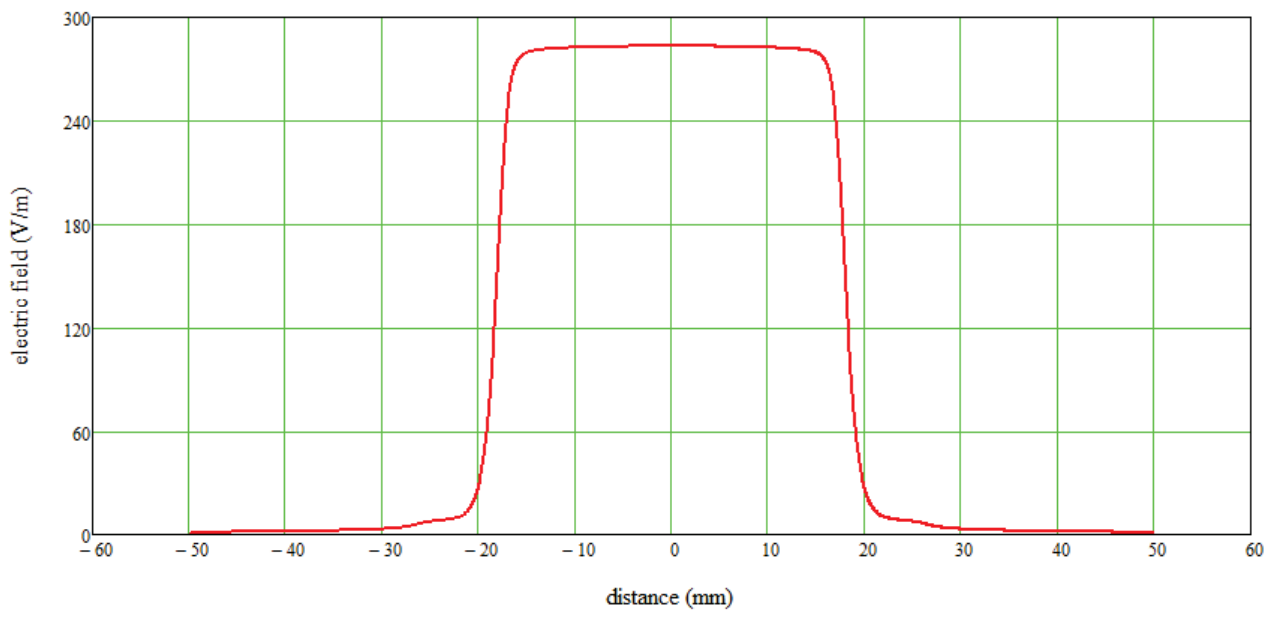

(b)

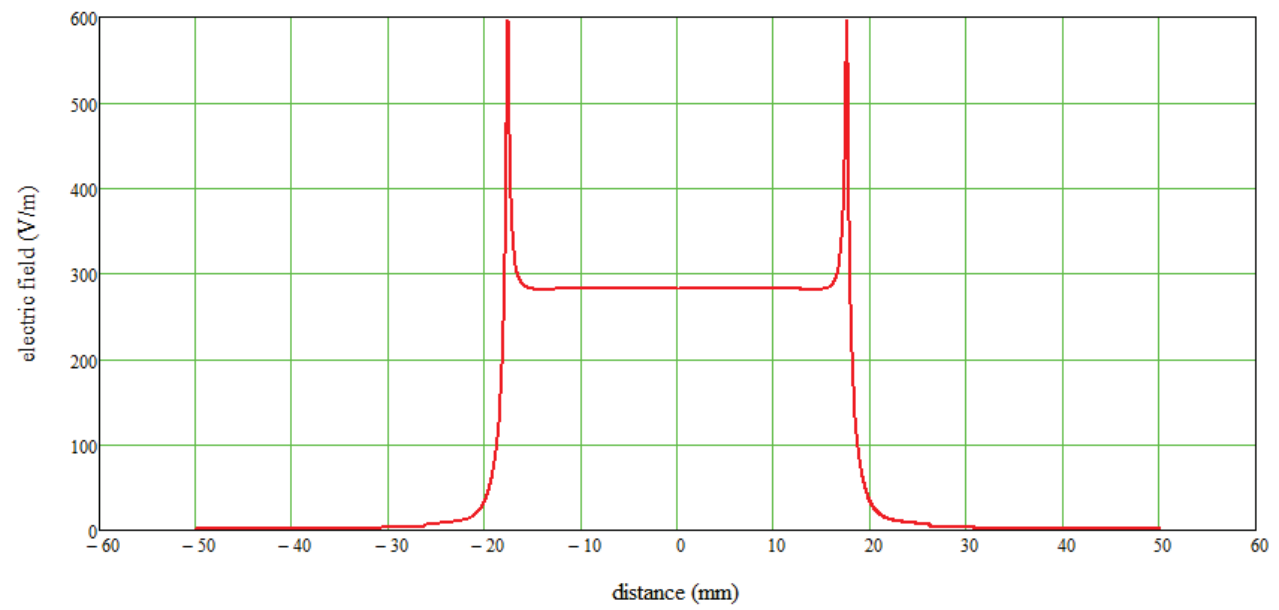

(c)

Fig. 5 Electric field distribution inside the cell provided by Maxwell software for $1 \mathrm{~V}$ applied on the cell and cell heated at $40^{\circ} \mathrm{C}$ (a) overall view

(b) variation of the electric field component $\mathrm{E}_{\mathrm{x}}$ along the Oy axis i.e., along the laser path

(c) variation of the electric field component $\mathrm{E}_{\mathrm{x}}$ along a line parallel to $\mathrm{Oy}$ and at $0.1 \mathrm{~mm}$ distance from the ceramic cylinder; the two maxima correspond to the triple 'point' referred in the text.

The coordinates are defined in Fig. 2 (b) 


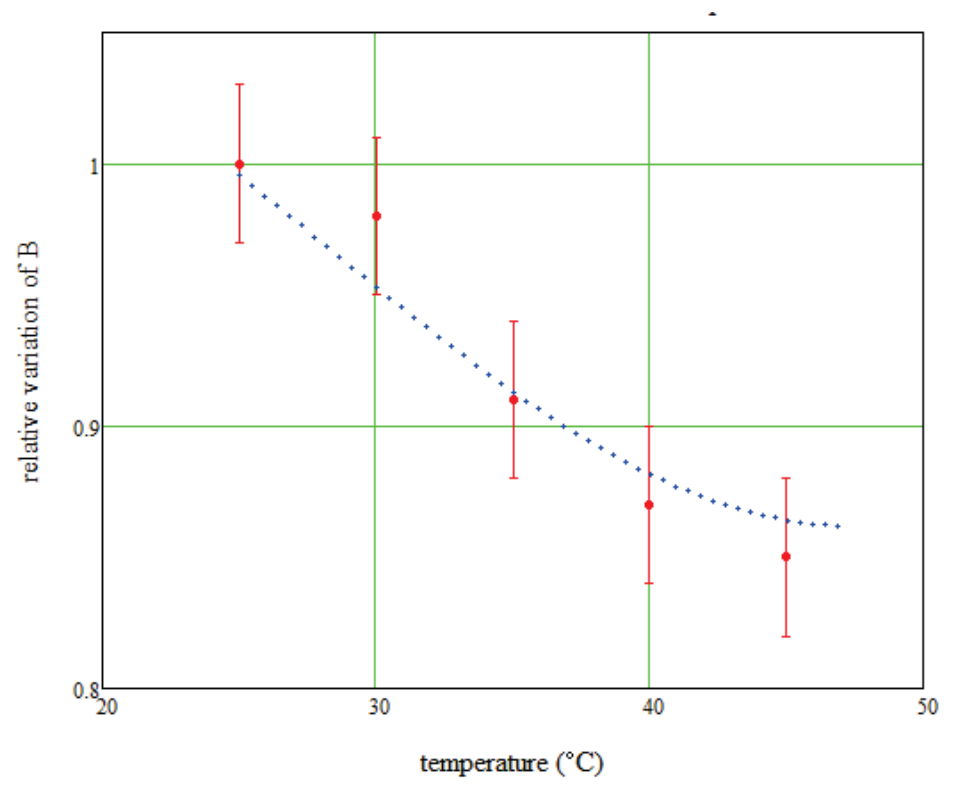

Fig. 6 Relative temperature variation of the Kerr 'constant' for water: experimental data (full circles) is compared with Eq. (2) (dotted line)

water and the real Kerr signal drops to zero, indicating that no electric field is generated after this event. As demonstrated by Fig. 7(b), this unwanted and extremely important phenomenon cannot be identified by simply measuring the voltage applied across the cell!

The importance of having a direct electric field measurement inside the treated water is obvious: the extreme fields predicted by voltage measurement may not be generated inside the cell and in such cases the PEF sterilization results will be extremely disappointing without any obvious reasons. The electric breakdown inside the cell could sometimes be observed as a luminous phenomenon that indicated the breakdown was initiated in the triple point circular region. Damage to the ceramic material in the triple point region was also evident after a large number of high field tests were performed during which electrical breakdown was observed.

\section{MAIN RESULTS OF THE PEF EXPERIMENTS}

The aim of the experiments was to prove that a PEF system in which no conduction current is present is capable of producing a very important reduction in the initial number of microorganisms.

As discussed above, the only reliable way to correctly estimate the electric field acting on the microbes inside the cell is to experimentally monitor the Kerr-effect signal $I(t)$ during each shot. Eq. (3) is then used to obtain $E_{w}(t)$ and Eq. (5) to provide the time variation of the central field. Fig. 8 shows a typical example in which a Kerr signal, obtained using an optical arrangement with a quarter wave-plate present, is analyzed with the corresponding central electric field also presented. The 'noise' present in the electric field results at low amplitudes is an artifact due to the inevitable large errors when analyzing low amplitude Kerr signals. Full details on the errors related to Kerr signal analysis are provided in [24]. The results of the PEF experiments presented below are expressed in terms of the peak central electric field calculated as described above.

PEF experiments were performed on Escherichia coli in water with the volume of the sample, as already mentioned, being $4.48 \mathrm{~cm}^{3}$. Strain number for Escherichia coli used was W3110 and was obtained from the stock collection of University of Nottingham (UK). The viability of the bacteria (ratio of the concentration of surviving bacteria to the initial concentration) was measured using standard procedures: the bacteria were diluted in a serial fashion, spread onto Agar plates in triplicate, grown overnight and counted with the result expressed in $\log _{10} \mathrm{CFU} / \mathrm{ml}$. The media used to grow strains was Nutrient Broth (Oxoid) and cells were grown at $37^{\circ} \mathrm{C}$. With one exception, the starting population was $10^{6} \mathrm{CFU} / \mathrm{ml}$. Cells were taken out of culture media by centrifugation at $3000 \cdot \mathrm{g}$ and re-suspended in water prior to dilution. The Agar used to plate bacteria post treatment was Nutrient Agar (Oxoid). The detection limit i.e., the bacterial count, was about $100 \mathrm{CFU} /$ plate.

As already mentioned, the PEF experiments were all conducted at $40{ }^{\circ} \mathrm{C}$ with either 50 or 100 identical shots being performed. In each experiment there were a number of 'zero-field' (non-treated) water samples taken from the microbial suspension bottle before the start of every test, and counted to determine the starting population. One water sample, termed control 1, was contained in a cell similar to that used in the PEF treatment (i.e., in contact with ceramic electrodes) and was placed inside the heater of Fig. 2c during the whole duration of a test, usually about two hours, during which it had the same thermal history as the treated sample. Another sample, control 2 , was kept in a glass tube at $40^{\circ} \mathrm{C}$ in the laboratory where the samples were prepared, together with another set of three samples (controls 3 to 5) which were kept at the room temperature of about $21{ }^{\circ} \mathrm{C}$. The counts from the two heated controls (control 1 and 2) were always extremely close one to another and demonstrated that the microorganisms did undergo 

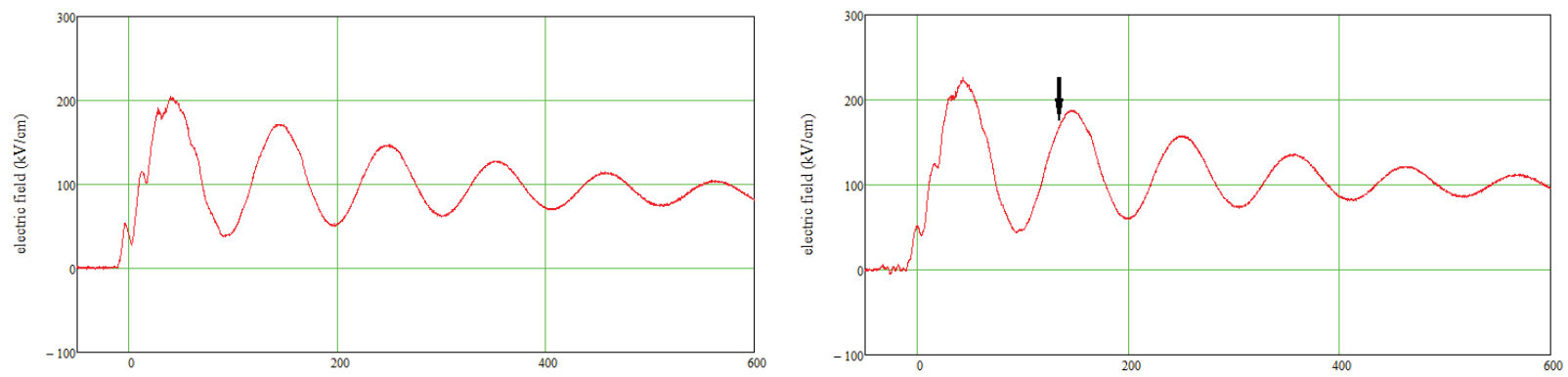

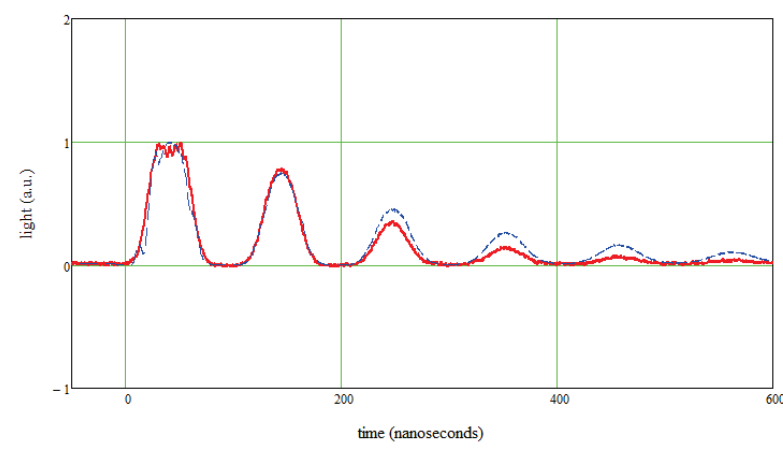

(a)

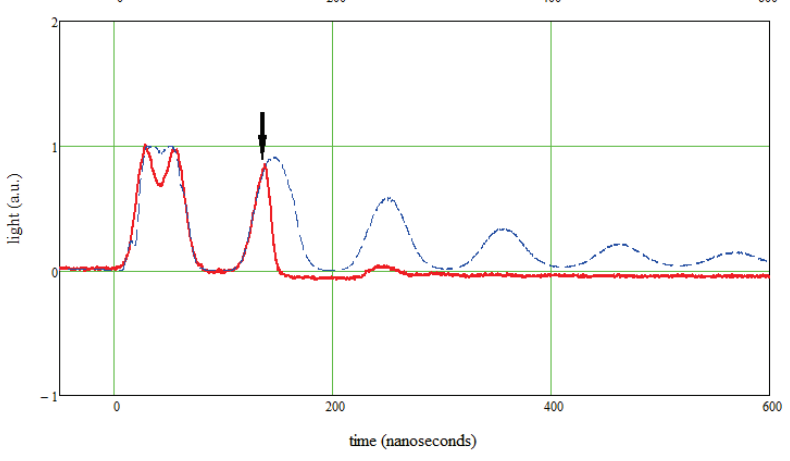

(b)

Fig. 7 Kerr results obtained during preliminary testing of the present PEF treatment system for peak electric fields: (a) $200 \mathrm{kV} / \mathrm{cm}$ and (b) $225 \mathrm{kV} / \mathrm{cm}$

upper traces: time variation of the central electric field inferred from voltage measurement across the cell lower traces: Kerr signal (line) compared with theoretical prediction made using Eq. (1) and voltage measurement (broken line) Arrows in (b) indicate the instant at which an electrical breakdown inside the water is clearly observed on the Kerr signal. Note that no such phenomenon appears on the electric field and the predicted Kerr signals, both based on voltage measurement across the cell. This proves that without electric field Kerr monitoring, a PEF experiment in which conduction currents are not present cannot be properly controlled and understood.

some replication, as was expected, in contrast to controls 3 to 5 for which no replication was observed. The results demonstrate that, at least apparently, no toxic effects from the ceramics were present.

Fig. 9 presents the main results obtained: the variation of the $\log _{10} \mathrm{CFU} / \mathrm{ml}$ reduction as a function of the applied central peak electric field. Basically, a reduction between $4 \log _{10} \mathrm{CFU} / \mathrm{ml}$ and $6 \log _{10} \mathrm{CFU} / \mathrm{ml}$ is evident for fields between $130 \mathrm{kV} / \mathrm{cm}$ and

$200 \mathrm{kV} / \mathrm{cm}$. Also presented in Fig. 9 are results reported in [6] obtained with an invasive PEF technique by applying 70 electric electric impulses with strength up to $110 \mathrm{kV} / \mathrm{cm}$ and $130 \mathrm{~ns}$ duration at a water temperature maintained close to $50{ }^{\circ} \mathrm{C}$. Qualitatively, the comparison between the two sets of data suggests that the non-invasive PEF method produces similar effects to the present PEF technique. The major difference is that while during the invasive PEF the conduction current flowing through the sample was $860 \mathrm{~A}$ [6], in the present tests only displacement current was present. As already demonstrated, the Joule effect in the present PEF tests can be neglected and the electrostatic energy density which characterizes the electrostatic stresses formed in biological membranes is given by $\frac{\varepsilon_{0} \varepsilon_{r} E^{2}}{2}$. This energy density at $E \approx 200 \mathrm{kV} / \mathrm{cm}$ is about $0.13 \mathrm{~J} / \mathrm{cm}^{3}$, a very low figure.

\section{CONCLUSIONS AND THE WAY AHEAD}

The research programme presented here has introduced a PEF technique that does not use conduction currents, has a negligible Joule effect and has also highlighted its potential application to industrial food processing. Due to the considerable technical effort and the corresponding budget, both required to develop a novel non-invasive technology at an industrial level, experiments were performed to answer important issues. The major findings can be summarized as:

- undoubtedly, a PEF technique without conduction currents can produce a very significant reduction in the initial concentration of Escherichia coli bacteria

- qualitatively the results suggest that, when similar electric field impulses are applied, this PEF system produces effects comparable to the standard invasive PEF systems, but using much less energy

- the results show that, only up to 100 shots are required to obtain a significant $\log$ reduction, with each shot an electric field of between $150 \mathrm{kV} / \mathrm{cm}$ and $200 \mathrm{kV} / \mathrm{cm}$ necessarily being generated in water. The corresponding electric field energy density required is only about $0.1 \mathrm{~J} / \mathrm{cm}^{3}$

- when PEF experiments are performed without conduction current, monitoring of the electric field by Kerr-effect is essential.

Based on the findings obtained, it is possible to think about the design of a future non-invasive PEF system for industrial processing of pre-packed food. The packaged food, solid or liquid, would be immersed in water maintained at a convenient temperature (possibly less than $40^{\circ} \mathrm{C}$ ) with a remote pulsed power generator producing a series of very intense electric fields impulses. As modern repetitive pulsed power generators can easily operate at a PRF of say $100 \mathrm{~Hz}$ (although $\mathrm{kHz}$ 

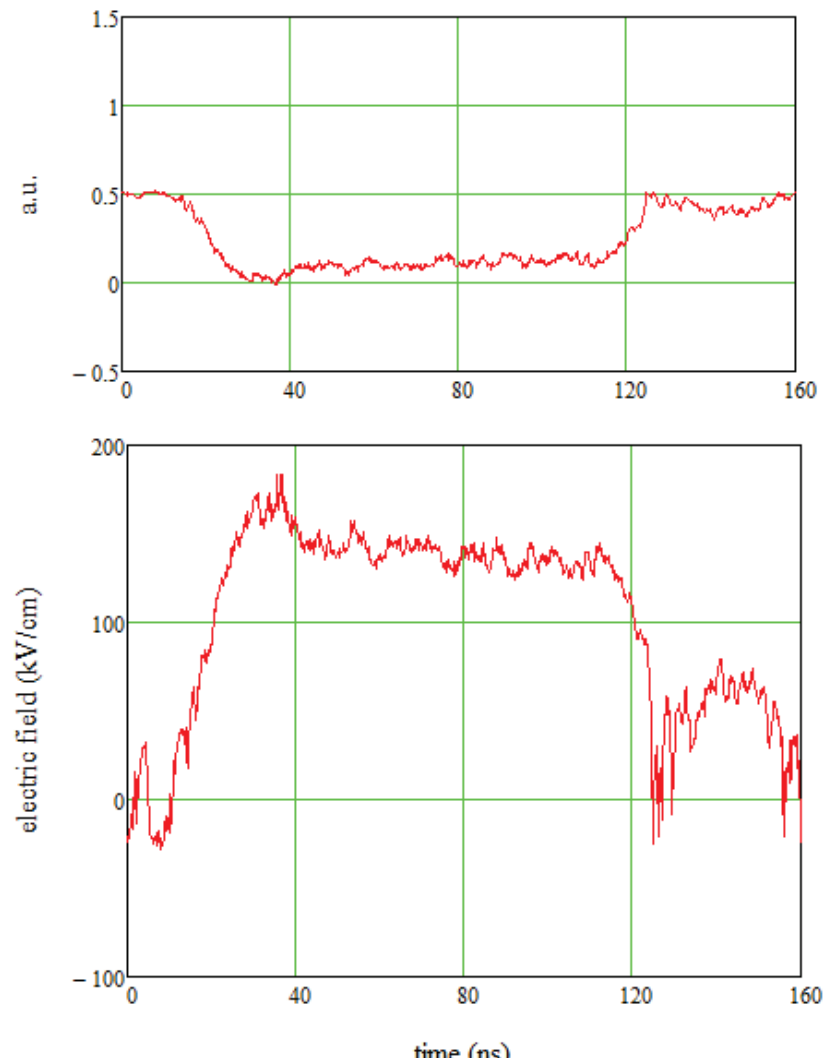

Fig. 8 Monitoring the electric field inside the cell during a PEF test using electro-optic diagnostic (upper) Kerr effect signal with quarter wave-plate present and (lower) the corresponding calculated central electric field using both Eq. (3) and Eq. (5) The shape of the voltage impulse applied on the cell is similar to that presented in Fig. 4(b)

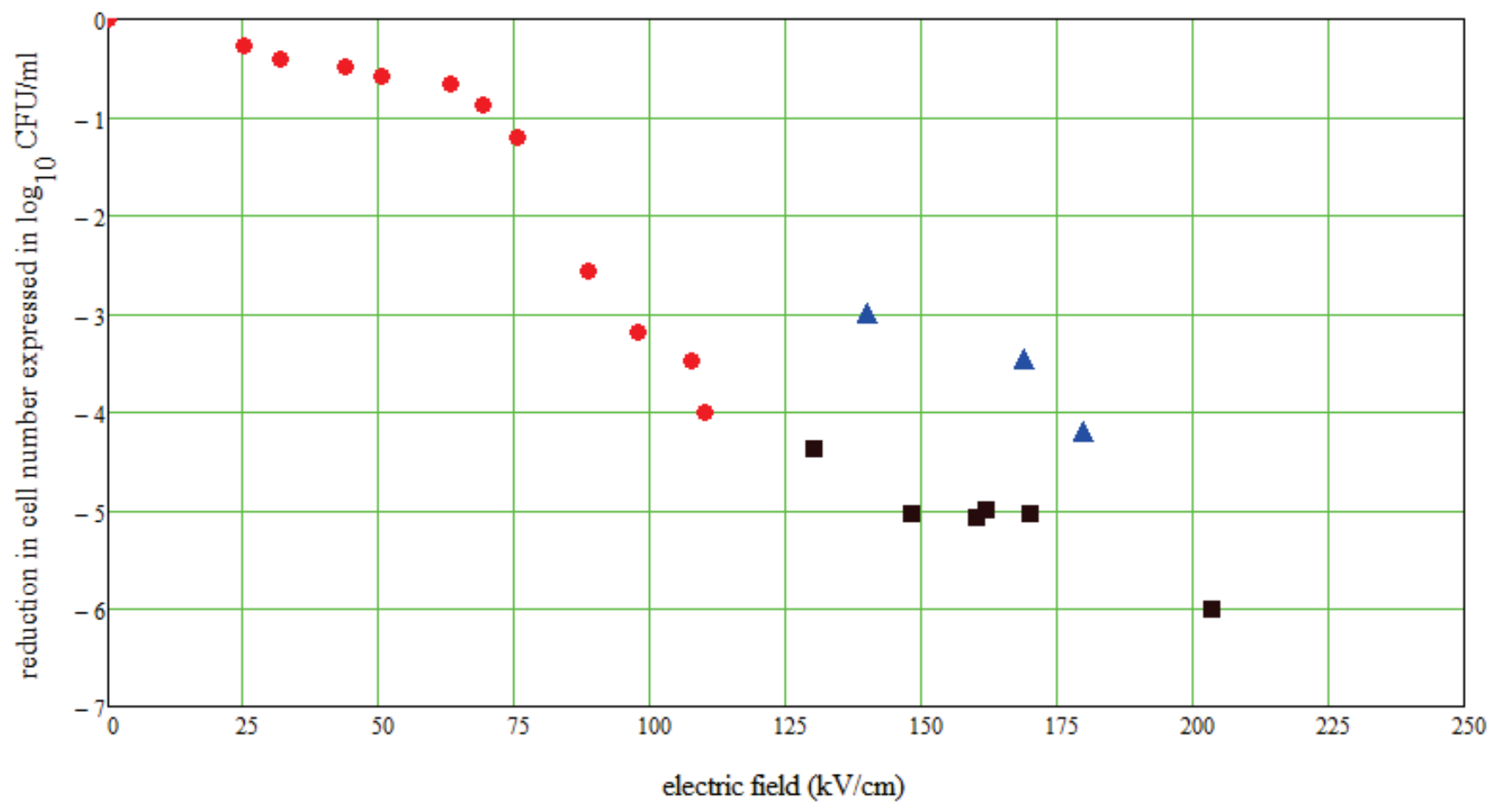

Fig. 9 Results obtained from PEF experiments with no conduction current performed at $40{ }^{\circ} \mathrm{C}$; full squares are for 100 shots and full triangles for 50 shots; results reported in [6] using invasive PEF technology with a conduction current up to 860 A performed at $50{ }^{\circ} \mathrm{C}$ by applying 70 shots are shown as full circles; in both cases the treated water contained Escherichia coli 
operation is also possible) the processing will take only about one second. Although a large number of issues still remain to be answered, the present work clearly opens the door for the novel technology.

\section{REFERENCES}

[1] K. H. Schoenbach, R. P. Joshi, R. H. Stark, F. C. Dobbs and S. J. Beebe, "Bacterial Decontamination of Liquids with Pulsed Electric Fields", IEEE Trans. Dielectrics and Elec. Ins., 7, pp.637-645, 2000

[2] P. R. Chalise, S. Perni, G. Shamaet, B. M. Novac, I. R. Smith, and M. G. Kong, "Lethality Mechanisms in Escherichia Coli Induced by Intense Sub-Microsecond Electrical Pulses", Appl. Phys. Lett. 89, 153902, 2006

[3] J.C. Weaver and K.H. Schoenbach, "Biodielectrics", IEEE Trans. Dielelectrics and Elec. Ins., 5, pp.715-716, 2003

[4] G.V. Barbosa-Canovas et al (Eds), Novel Food Processing Technologies, London: CRC Press, 2005

[5] K.H. Schoenbach, F.E. Peterkin, R.W.Alden and S.J. Beebe, "The Effect of Pulsed Electric Fields on Biological Cells: Experiments and Applications", IEEE Trans. on Plasma Science., 25, pp.284-292, 1997

[6] R. Narsetti, R.D. Curry, K.F. McDonald, T.E. Clevenger and L.M. Nichols, "Microbial Inactivation in Water Using Pulsed Electric Fields and Magnetic Pulse Compressor Technology", IEEE Trans. on Plasma Science, 34, pp. 1386-1393, 2006

[7] M.P.J. Gaudreau, T. Hawkey, J. Petry and M.A.. Kempkes, "A Solid State Pulsed Power System for Food Processing", Proc. 13th IEEE Int. Pulsed Power Conf., pp. 1174-1177, 2001

[8] M. Kempkes, M. Gaudreau, T. Hawkey and J. Petry, "Scale-up of PEF Systems for Food and Waste Streams", Proc. 16th IEEE Int. Pulsed Power Conf. , pp. 1064-1067, 2007

[9] B.M. Novac, P. Sarkar, I.R. Smith, W. Whittow and C. Greenwood, "An Innovative and Non-invasive Technology for PEF Food Processing", Proc.17th IEEE Int. Pulsed Power Conf., pp. 737-741, 2009

[10] B.M. Novac, P. Sarkar, I.R. Smith, F. Banakhr, C. Greenwood, L. Pecastaing, R. Ruscassie, A. De Ferron and P. Pignolet, "A Novel and Non-invasive Pulsed Electric Field Technique for Industrial Food Processing", IET European Pulsed Power Conference, CERN, Geneva, Switzerland, 2009

[11] S.H. Jayaram, "Sterilization of Liquid Foods by Pulsed Electric Fields", IEEE Electrical Insulation Magazine, 16, No. 6, pp. 17-25, 2000

[12] S. Toepfl, V. Heinz, and D. Knorr, "High intensity pulsed electric fields applied for food preservation", Chemical Engineering and Processing, 46, pp.537-546, 2007

[13] N.I. Lebovka and E. Vorobiev "On the origin of the deviation from the first-order kinetics in inactivation of microbial cells by pulsed electric fields", International Journal of Food Microbiology, 91, pp 83-89, 2004

[14] X. A. Zeng, S. J. Yu, L. Zhang and X.D. Chen, "The effects of AC electric field on wine maturation", Innovative Food Science and Emerging Technologies, 9, pp. 463-468, 2008

[15] D. Wetz, K. Truman, J. Dickens, J. Mankowski, and A. Neuber," Short Pulse Electric Field Sterilisation of Liquid Media", 14th IEEE Int. Pulsed Power Conf., Dallas, Texas, June 15-18, M. Giesselmann and A. Neuber, Eds., pp. 1124-1127, 2003

[16] I. Timoshkin, I.S. MacGregor, R. Fouracre, B. Crichton and J. Anderson, "Transient electrical field across cellular membranes - pulsed electric field treatment of microbial cells", Journal of Physics D: Applied Physics, 39 pp. 596-603, 2006

[17] M. Pizzichemi, "Pulsed Electric Field inactivation of microbial cells: the use of ceramic layers to increase the efficiency of treatment", Nuclear Physics B (Proc. Suppl.), 197, pp. 374-377, 2009

[18] M. Zahn, Y. Ohki, D. B. Fenneman, R. J. Gripshover and V. H. Gehman, JR., "Dielectric Properties of Water and Water/Ethylene Glycol Mixtures for Use in Pulsed Power System Design", Proc. IEEE, vol. 74, pp. 1182-1221, 1986

[19] http://13ndt.com/ (accessed June 2013)

[20] http://www.highvoltageprobes.com (accessed June 2013)

[21] http://www.pearsonelectronics.com/products/current-monitors (accessed June 2013)

[22] http://www.cadence.com/products/orcad/pspice_simulation/pages/defau lt.aspx (accessed June 2013)

[23] http://www.ansys.com/Products/Simulation+Technology/Electromagneti cs/Electromechanical+Design/ANSYS+Maxwell (accessed June 2013)
[24] B. M. Novac, F. A. Banakhr, I. R. Smith, L.Pécastaing, R. Ruscassié, A. S. De Ferron, and P. Pignolet "Determination of the Kerr Constant of Water at $658 \mathrm{~nm}$ for Pulsed Intense Electric Fields", IEEE Trans. on Plasma Science, accepted for publication, 2012

[25] "Kerr coefficients of nitrobenzene and water," Nat. Bureau Stand., Boulder, CO, Final Rep. AFWL-TR-76-117, 1976

[26] B. Cadilhon, L. Pecastaing, T. Reess, A. Gibert, "Low stray inductance structure to improve the rise-time of a Marx generator", IET Electric Power Applications, vol. 2, pp. 248-255, 2008

\section{APPENDIX 1}

\section{Energy dissipation during PEF processing}

In what follows, for both invasive and non-invasive PEF, a cylindrical processing volume is considered, with axis length $d$ and cross section area $A$, in which the electric field and the current are both generated along the axis.

For invasive PEF the energy density dissipated by the Joule effect is:

$$
W_{\text {invasive }}=\frac{\int_{o}^{t} \frac{V(t)^{2}}{R_{\text {ohmic }}} d t}{A d}=\sigma \int_{o}^{t} E(t)^{2} d t
$$

where $R_{\text {ohmic }}=\frac{d}{\sigma A}$ and $V(t)=E(t) d$.

For non-invasive PEF the energy density dissipated in the water by the dipole friction mechanism is:

$$
W_{\text {non-invasive }}=\frac{\int_{o}^{t}\left(j_{\text {disp }} A\right)^{2} R_{E S R} d t}{A d}=\frac{\varepsilon_{0} \varepsilon_{w} \tan \delta}{\omega} \int_{o}^{t}\left(\frac{d E(t)}{d t}\right)^{2} d t
$$

where $j_{\text {disp }}=\varepsilon_{0} \varepsilon_{w} \frac{d E}{d t}$ is the displacement current density, $R_{E S R}=\frac{d \tan \delta}{\omega \varepsilon_{0} \varepsilon_{w} A}$ is the equivalent series resistance (see text) and $\tan \delta$ is the loss tangent.

\section{a) Sinusoidal impulse}

Firstly consider an electric field impulse having the shape of a sinusoid (Fig. A1(a)) with $E(t)=E_{0} \sin (\omega t)$ and a duration $\mathrm{T} / 2$, where $T=\frac{2 \pi}{\omega}$ is the period. The corresponding energy densities are:

$$
W_{\text {invasive }}=\sigma E_{0}{ }^{2} \frac{T}{4} \text { and } W_{\text {non-invasive }}=\varepsilon_{0} \varepsilon_{w} \tan \delta E_{0}{ }^{2} \frac{\pi}{2}
$$

\section{b) Trapezoidal impulse}

Secondly, consider an electric field impulse having the shape of a trapezoid (Fig. A1(b)) with an initial ramp increasing linearly from zero to amplitude $E_{0}$ in time $t_{r}$ with $E(t)=\frac{E_{0}}{t_{r}} t$ followed by a constant plateau of width $T p$ and amplitude $E_{0}$ and ending with a decreasing ramp as a mirror image of the initial 
ramp. This impulse corresponds closely to an impulse generated by a pulse forming line (PFL).

The corresponding energy densities are:

$W_{\text {invasive }}=\sigma E_{0}^{2}\left(\frac{2}{3} t_{r}+T_{p}\right)$

$W_{\text {non-invasive }}=\varepsilon_{0} \varepsilon_{w} \tan \delta E_{0}{ }^{2} \frac{1}{0.35 \pi}$

Some useful numerical examples are provided below for water at $40{ }^{\circ} \mathrm{C}$ and having $\sigma=500 \mu \mathrm{S} / \mathrm{m}, \varepsilon_{0} \varepsilon_{\mathrm{w}} / \sigma \approx 1.3 \mu \mathrm{s}$ and $\tan \delta \approx 0.005$ (see text).

In the case of a sinusoidal signal with $T / 2=100 \mathrm{~ns}$, the ratio between the two energies is: $\left(\frac{W_{\text {invasive }}}{W_{\text {non-invasive }}}\right)_{\text {sin usoid }} \approx 5$ while for $T / 2=200 \mathrm{~ns}$ the ratio is doubled to 10 .

In the case of a trapezoidal impulse, for $t_{r}=30 \mathrm{~ns}$ and $T p=100 \mathrm{~ns}$, the ratio is: $\left(\frac{W_{\text {invasive }}}{W_{\text {non-invasive }}}\right)_{\text {trapezoid }} \approx 20$ and if the impulse duration increases to $T p=200 \mathrm{~ns}$ the ratio raises to 37 .

Finally, the non-invasive energy dissipated in a sinusoidal impulse is about 1.7 times larger than that corresponding to a trapezoidal impulse (both having the same peak field $\mathrm{E}_{0}$ ).

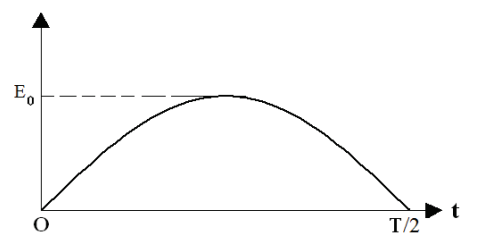

(a)

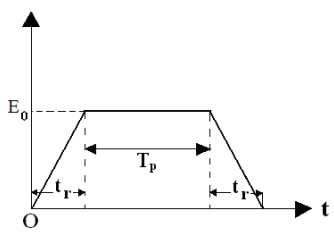

(b)

Fig. A1 (a) sinusoidal impulse; (b) trapezoidal impulse 


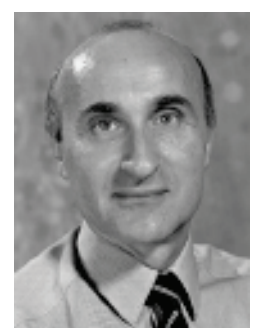

Bucur M. Novac (SM'08) received the M.Sc. and $\mathrm{Ph} . \mathrm{D}$. degrees from the University of Bucharest. He joined the Loughborough University, UK in 1998 and is currently Professor of Pulsed Power.

His research interests include compact high-power systems, explosively and electromagnetically driven magnetic flux compression generators and their applications, electromagnetic launchers, ultrafast magneto and electro-optic sensors and 2-D modeling of pulsed-power systems.

Dr. Novac is a Chartered Engineer and a Fellow of The Institution of Engineering and Technology. $\mathrm{He}$ is also a member of the Organizing Committees for the IEEE IPMHV, for the Euro-Asian Pulsed Power and for the Megagauss conferences.

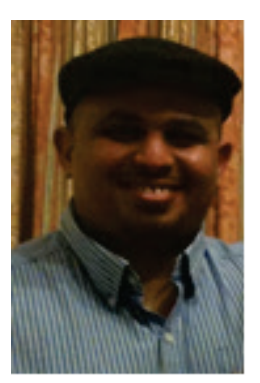

Fahd A. Banakhr was born in Saudi Arabia and he has been awarded an Associate Diploma from Yanbu Industrial College, a BEng in Electronics and Industrial Control Engineering from the University of Nottingham, UK and a MSc in Electronics Instrumentation Systems from the University of Manchester, UK. He has recently completed PhD studies with the Pulsed Power Group at Loughborough University, UK.

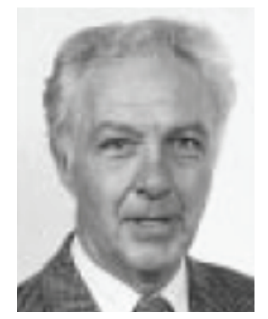

Ivor R. Smith received the B.Sc. and Ph.D. degrees from the University of Bristol, U.K., after completing a student apprenticeship at the Witton Works of the General Electric Company.

He then became a Lecturer in electrical engineering at the University of Birmingham, Birmingham, U.K., subsequently being promoted to Lecturer and Reader and being awarded the degree of D.Sc. for his continued research contribution. He then moved to Loughborough University to become Professor of Electrical Power Engineering, and serving as Head of Department, Dean of Engineering and Pro-Vice Chancellor. For some 25 years he has been active in research in many aspects of the production, conditioning, and utilization of large pulses of electrical energy, and his work has brought in very substantial funding from a wide range of sponsors.

Dr. Smith is a Chartered Engineer, a Fellow of The Institution of Engineering and Technology, and a Fellow of the Royal Academy of Engineering.

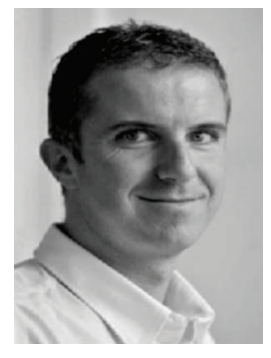

Laurent Pécastaing was born in Bayonne, France, in 1974. He received the Ph.D. degree and the Research Directorship Habilitation in electrical engineering from the Université de Pau et des Pays de l'Adour, Pau, France, in 2001 and 2010, respectively. $\mathrm{He}$ is currently a Lecturer with the Laboratoire SIAME, Université de Pau et des Pays del'Adour. His research interests are focused on high-power microwave (HPM) sources, compact pulsed power devices, including pulse-forming lines or Marx generators, and ultrafast transient probes.

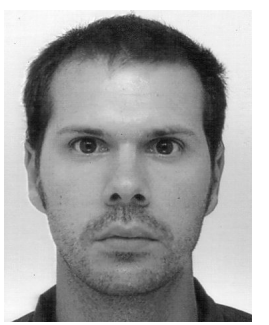

Robert Ruscassié received the Graduate degree in electrical engineering in 2001, and the Ph.D degree in 2005, both from the Université Montpellier II, Montpellier, France.

$\mathrm{He}$ is currently a lecturer- researcher at the SIAME laboratory, Université de Pau et des Pays de l'Adour. His current research interests focus on energy conversion and associated metrology for pulsed power applications.

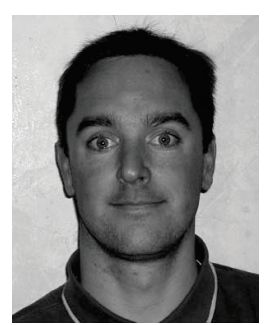

Antoine Silvestre de Ferron was born in Tarbes, France, in 1977. He received the Ph.D. degree in electrical engineering from the Université de Pau et des Pays de l'Adour (UPPA), Pau, France, in 2006.

From 2006 to 2008, he was a Researcher with the Atomic Energy Comission (CEA), Le Barp, Francea French-government-funded technological research organization. He is currently an Engineer with the Laboratoire SIAME, UPPA. His research interests include high pul sed power generation for military and civil applications and combined high-voltage transient probes.

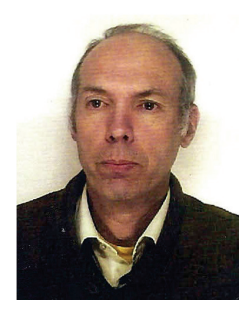

Pascal Pignolet was born in Rennes, France, in 1951. $\mathrm{He}$ received the Ph.D. degree in Gas and Plasma Physics from the University of Orléans, France, in 1980 and the higher Doctorate of Science in 1984 for his work devoted to the spectroscopic study of non-resonant laser-atom interaction. He is currently a Professor with the University of Pau (France) and with the SIAME laboratory. His main research interest is currently focused on Pulsed Power domain, Materials for the Electrical Engineering and Laser applications. 